\title{
Properties of an alkali-thermo stable xylanase from Geobacillus thermodenitrificans A333 and applicability in xylooligosaccharides generation
}

\author{
Loredana Marcolongo - Francesco La Cara • \\ Alessandra Morana • Anna Di Salle · Giovanni del Monaco • \\ Susana M. Paixão $\cdot$ Luis Alves $\cdot$ Elena Ionata
}

Received: 11 November 2014 / Accepted: 3 February 2015/Published online: 17 February 2015

(C) Springer Science+Business Media Dordrecht 2015

\begin{abstract}
An extracellular thermo-alkali-stable and cellulase-free xylanase from Geobacillus thermodenitrificans A333 was purified to homogeneity by ion exchange and size exclusion chromatography. Its molecular mass was $44 \mathrm{kDa}$ as estimated in native and denaturing conditions by gel filtration and SDS-PAGE analysis, respectively. The xylanase (GtXyn) exhibited maximum activity at $70{ }^{\circ} \mathrm{C}$ and $\mathrm{pH}$ 7.5. It was stable over broad ranges of temperature and $\mathrm{pH}$ retaining $88 \%$ of activity at $60{ }^{\circ} \mathrm{C}$ and up to $97 \%$ in the $\mathrm{pH}$ range $7.5-10.0$ after $24 \mathrm{~h}$. Moreover, the enzyme was active up to $3.0 \mathrm{M}$ sodium chloride concentration, exhibiting at that value $70 \%$ residual activity after $1 \mathrm{~h}$. The presence of other metal ions did not affect the activity with the sole exceptions of $\mathrm{K}^{+}$that showed a stimulating effect, and $\mathrm{Fe}^{2+}, \mathrm{Co}^{2+}$ and $\mathrm{Hg}^{2+}$, which inhibited the enzyme. The xylanase was activated by non-ionic surfactants and was stable in organic solvents remaining fully active over $24 \mathrm{~h}$ of incubation in $40 \%$ ethanol at $25^{\circ} \mathrm{C}$. Furthermore, the enzyme was resistant to most of the neutral and alkaline proteases tested. The enzyme was active only on xylan, showing no marked preference towards xylans from different origins. The hydrolysis of beechwood xylan and agriculture-based biomass materials yielded $x y-$ looligosaccharides with a polymerization degree ranging from 2 to 6 units and xylobiose and xylotriose as main
\end{abstract}

L. Marcolongo · F. La Cara (凹) - A. Morana - A. Di Salle . G. del Monaco · E. Ionata

Institute of Biosciences and Bioresources, National Research Council, Via Pietro Castellino, 111, 80131 Naples, Italy

e-mail: francesco.lacara@cnr.it

S. M. Paixão · L. Alves

Laboratório Nacional de Energia e Geologia, Instituto Nacional de Energia e Geologia IP, Unidade de Bioenergia, Estrada do Paço do Lumiar, 22, 1649-038 Lisbon, Portugal products. These properties indicate G. thermodenitrificans A333 xylanase as a promising candidate for several biotechnological applications, such as xylooligosaccharides preparation.

Keywords Thermo-alkali stable xylanase - Geobacillus thermodenitrificans A333 - Agro-derived lignocellulosics . Xylooligosaccharides

\section{Introduction}

Worldwide there is a growing interest in the utilization, for bioenergetic purposes, of lignocellulosic materials (LCMs), the most abundant and renewable resources on Earth that constitute a large component of the wastes originated from municipal, agricultural, forestry and some industrial sources. In this scenario, xylanolytic enzymes of microbial origin play an important role in the bioconversion of LCMs into high value products as they act on the xylan, the main component of hemicellulose, which is the most represented polysaccharide in plant biomass after cellulose (Bastawde 1992; Timell 1967). Xylan is a heteropolysaccharide consisting of a linear backbone of 1,4- $\beta$-linked D-xylose units, substituted with various side groups such as 4-O-methyl-D-glucuronosyl, $\alpha$-arabinofuranosyl residues and others. Due to its heterogeneity, the complete hydrolysis of xylan requires a system of enzymes including endo- $\beta$-D-xylanases, $\beta$-D-xylosidases, $\alpha$-L-arabinofuranosidases, $\alpha$-D-glucuronidases, acetylxylan esterases, ferulic and $p$-coumaric acid esterases that synergically act on the linear chain as well as on the side chains (Juturu and Wu 2012). Among them, the xylanases, whose function is to randomly cleave the linear chain internal linkages releasing xylooligosaccharides (XOS), are catalysts of significant industrial importance, due to their high 